\title{
Selected Papers from the 2nd Edition of Global Conference on Catalysis, Chemical Engineering and Technology (CAT 2018)
}

\author{
Stanislaw Dzwigaj ${ }^{1, *}$ and Christophe Len ${ }^{2}$ (I) \\ 1 Laboratoire de Réactivité de Surface, Sorbonne Université-CNRS, UMR 7197 Campus Pierre et Marie \\ Curie, 4, Place Jussieu, 75252 Paris, France \\ 2 Chimie ParisTech-CNRS, Institute of Chem. For Life \& Health Sciences, 11 rue P\&M Curie, \\ 75231 Paris, France; christophe.len@utc.fr \\ * Correspondence: stanislaw.dzwigaj@sorbonne-universite.fr
}

Received: 13 May 2020; Accepted: 4 June 2020; Published: 10 June 2020

The present Special Issue concerns the papers which have been presented at the second edition of the Global Conference on Catalysis, Chemical Engineering \& Technology (CAT 2018) that promote linkage of the catalytic science, engineering and technology. The topics of the conference have covered various aspects of catalysis in all of its diversity, as well as other areas on the boundaries such as environmental protection, energy, sustainability, green chemistry, fine chemistry, biotransformation, surface chemistry and enzyme and microbial technology.

Sadek et al. [1] studied cobalt based catalysts supported on two kinds of beta zeolite for application in Fischer-Tropsch Synthesis. Co-containing beta zeolite catalysts prepared by wet impregnation and two-step postsynthesis method were investigated. The activity of the catalysts was examined in Fischer-Tropsch synthesis, performed at $30 \mathrm{~atm}$ and $260^{\circ} \mathrm{C}$. The physicochemical properties of all systems were investigated by means of $\mathrm{XRD}$, in situ $\mathrm{XRD}$, temperature programmed desorption of $\mathrm{NH}_{3}$, XPS, temperature programmed reduction of $\mathrm{H}_{2}$ and TEM. Among the studied catalysts, the best results were obtained for the samples prepared by two-step postsynthesis method, which achieved CO conversion of about $74 \%$ and selectivity to liquid products of about $86 \%$. The distribution of liquid products for Red-Me- $\mathrm{Co}_{20}$ Beta was more diversified than for Red-Mi- $\mathrm{Co}_{20}$ Beta. Significant influence of the zeolite dealumination of mesoporous zeolite on the catalytic performance was observed in FTS. In contrast, for microporous catalysts the dealumination did not play such a significant role and the relatively high activity was observed for both non-dealuminated and dealuminated catalysts. The main liquid products of FTS on both mesoporous and microporous catalysts were $\mathrm{C}_{10}-\mathrm{C}_{14}$ isoalkanes and $\mathrm{n}$-alkanes. The iso-/n-alkanes ratio for dealuminated zeolite catalysts was three times higher than that for not dealuminated ones, and was related to the presence of different kinds of acidic sites in both zeolite catalysts.

Nishimura et al. [2] investigated hydroxymethylation of 2-furaldehyde (furfural) toward 5-hydroxymethyl-2-furaldehyde (HMF). In this work they examined various zeolites with an aqueous formaldehyde as a reagent in a batch and a flow reactor system. It was found that the zeolite beta gave high activity and good reusability with calcination treatment before each run for the target reaction in the batch system. The unique stability of the HMF yield in the liquid-flow system was also observed only in the case of zeolite beta. The effect of the $\mathrm{SiO}_{2} / \mathrm{Al}_{2} \mathrm{O}_{3}$ ratio in the zeolite beta suggested that hydrophobicity would be an important factor in faster hydroxymethylation with an aqueous formaldehyde reagent. The highest turnover frequency (TOF) for HMF production was found to be $2.4 \mathrm{~h}^{-1}$ in the case of zeolite beta with $\mathrm{SiO}_{2} / \mathrm{Al}_{2} \mathrm{O}_{3}=440$ in the batch reactor system. An approximately $30 \%$ yield for HMF was achieved under optimum conditions for zeolite beta catalysts. 
Stawowy et al. [3] investigated a series of cerium-based UiO-66 obtained via hydrothermal and sonochemical methods, using the same quantities of reagents (cerium ammonium nitrate (CAN), terephthalic acid $\left(\mathrm{H}_{2} \mathrm{BDC}\right)$ ) and solvents) in each synthesis. The impact of synthesis method and metal to linker ratio on the structural and textural properties of obtained $\mathrm{UiO}-66(\mathrm{Ce})$ structure defects, as well as their composition in terms of $\mathrm{Ce}^{4+} / \mathrm{Ce}^{3+}$ ratio, resulting from the missing linker and $\mathrm{CO}_{2}$ adsorption capacity was discussed. By using typical characterization techniques and methods, such as XRD, $\mathrm{N}_{2}$ and $\mathrm{CO}_{2}$ sorption, TGA, XPS, and SEM, it was shown that the agitation of reacting mixture during synthesis (caused by stirring or ultrasounds) allows to obtain structures that have more developed surfaces and fewer linker defects than when MOF was obtained in static conditions. The specific surface area was found to be of minor importance in the context of $\mathrm{CO}_{2}$ adsorption than the contribution of $\mathrm{Ce}^{3+}$ ions that were associated with the concentration of linker defects.

Finally, we sincerely thank all authors for their valuable contributions, as well as the editorial team of Catalysts for their kind support and fast responses. Without them, the Special Issue would not have been possible. Thank you very much.

Funding: There is no external funding.

Conflicts of Interest: The authors declare no conflict of interest.

\section{References}

1. Sadek, R.; Chalupka, K.A.; Mierczynski, P.; Rynkowski, J.; Gurgul, J.; Dzwigaj, S. Cobalt Based Catalysts Supported on Two Kinds of Beta Zeolite for Application in Fischer-Tropsch Synthesis. Catalysts 2019, 9, 497. [CrossRef]

2. Nishimura, S.; Shibata, A. Hydroxymethylation of Furfural to HMF with Aqueous Formaldehyde over Zeolite Beta Catalyst. Catalysts 2019, 9, 314. [CrossRef]

3. Stawowy, M.; Róziewicz, M.; Szczepańska, E.; Silvestre-Albero, J.; Zawadzki, M.; Musioł, M.; Łuzny, R.; Kaczmarczyk, J.; Trawczyński, J.; Łamacz, A. The Impact of Synthesis Method on the Properties and $\mathrm{CO}_{2}$ Sorption Capacity of UiO-66(Ce). Catalysts 2019, 9, 309. [CrossRef]

(C) 2020 by the authors. Licensee MDPI, Basel, Switzerland. This article is an open access article distributed under the terms and conditions of the Creative Commons Attribution (CC BY) license (http://creativecommons.org/licenses/by/4.0/). 